\title{
Experimental investigation on potential use of drilling parameters to quantify rock strength
}

\author{
C. R. Lakshminarayana ${ }^{1 *}$ (D) Anup Kumar Tripathi ${ }^{1}$ and Samir Kumar Pal ${ }^{2}$
}

\section{${ }^{*}$ Correspondence:}

crlaks042@gmail.com

${ }^{1}$ Department of Mining

Engineering, N.I.T.K,

Surathkal, Mangalore 575025

Karnataka, India

Full list of author information

is available at the end of the

article

\begin{abstract}
The uniaxial compressive strength (UCS) represents the strength of the rock. It frequently requires during the introductory phase of mining projects such as tunneling, rock excavation, blast hole designs, etc. Usually, the determination of UCS of rocks is carrying out in a concerned laboratory. The main drawback of determining the UCS in a laboratory requires at least five core samples of high-grade quality. Many problems and limitations are associated with removing the core, and also preparing the test specimen for UCS is tedious, time-consuming, and expensive. Therefore an attempt is made to develop an efficient indirect method to estimate the UCS of rocks without using the core samples. In this experimental investigation, the drilling response, such as thrust, is gathered by drill tool dynamometer considering the different drill operating parameters. The prediction model is developed with a regression technique using the measured thrust and calculated torque. The prediction capacity and validation of the model are carried out using the standard procedure. The experimental results show that the model could explain the variance in UCS up to $93.60 \%$. RMSE and MAPE values in terms of percentage are $3.49 \%$ and $11.27 \%$, respectively. Besides, the model's validation is checked for sandstone and limestone having the UCS $28 \mathrm{MPa}$ and $35 \mathrm{MPa}$, respectively, and yielded the best prediction results with an error of $8.51 \%$ and $8.01 \%$ suggesting that the developed model could predict the UCS of sedimentary rock types within acceptable error limit, and reasonably. The correlation of UCS of rocks and drilling specific energy is also tested and found that linear relationship between them with an $R^{2}$ value of $92.10 \%$.
\end{abstract}

Keywords: Rock strength, Drill tool dynamometer, Thrust, Torque, Multiple regressions

\section{Introduction}

The uniaxial compressive strength (UCS) is the critical property of rock strength to be tested frequently during many mining and civil engineering projects. The removal of core samples needed for laboratory testing is costly and often difficult to remove from the weathered and soft rocks. Besides, converting the samples into the laboratory test specimen is laborious and expensive. Therefore, the rock strength may not precisely be measured with the available inadequate number of rock samples, and the total rock-mass strength could be decided upon by the outcome obtaining from the same. This evaluation method may not yield proper results. To avoid that kind of problem, many empirical models have continually developed for the estimation of rock strength. In several rock

(c) The Author(s), 2021. Open Access This article is licensed under a Creative Commons Attribution 4.0 International License, which permits use, sharing, adaptation, distribution and reproduction in any medium or format, as long as you give appropriate credit to the original author(s) and the source, provide a link to the Creative Commons licence, and indicate if changes were made. The images or other third party material in this article are included in the article's Creative Commons licence, unless indicated otherwise in a credit line to the material. If material is not included in the article's Creative Commons licence and your intended use is not permitted by statutory regulation or exceeds the permitted use, you will need to obtain permission directly from the copyright holder. To view a copy of this licence, visit http:// creativecommons.org/licenses/by/4.0/. 
engineering projects associated with the mining environment, drilling is the fundamental operation to be included. Recently many researchers are using the drilling technique as a tool to determine the uniaxial compressive strength (UCS) of rocks. The different drill operating variables gathered during the rock drilling process are utilized in many investigations to evaluate the UCS. In the view of many rock engineering projects, an extended investigation is requiring to ensure the validity and correlation between drilling variables and the uniaxial compressive strength of rocks. The characterization of the rocks using drill operating parameters may also be helpful for mining engineering such as excavation, tunnel boring, blast hole design, quarrying, etc.

\section{Literature review}

In this section, the discussion on variations of different drill operating parameters during the drilling of rocks as well as other materials is made. In addition, the different drilling variables used for the estimation of rock properties are also discussed. During the rock drilling, Basarir and Karpuz [6] estimated the UCS of rocks using the drill machine operating parameters such as bit thrust and penetration rate (PR). From the data analysis, it could observe that the corresponding PR for the applied thrust was most impacting the UCS, followed by thrust. The prediction of rock strength and geological conditions around and in the blasting area could be possible using measurement while drilling (MWD) data [5, 15, 21]. Using the various bits at a different angle of attack, an attempt was made to determine the cuttability of rocks [22]. The experimental results revealed that the cutting thrust increases as the UCS of rock increases. During the rock cutting operation, Roxborough [24] found the linear relationship between the rock strength and cutting force. Erosy and Waller [13] studied the drillability of polycrystalline diamond compact (PDC) and diamond-impregnated drill bits. The experiment would carry out using the different bit speed and bit-thrust. Using the drilling data, it could develop a prediction model for drillability with the help of the regression method. From the analysis of variance (ANOVA), it is seen that bit-thrust and bit speed are substantially influencing the drillability respectively. The drillability of rocks relies on bit-thrust, bit speed, and rock properties [2]. A mathematical model was built to calculate the rock strength (UCS) using the rock's internal friction angle and cohesion parameters [17]. As a part of determining these parameters, drilling parameters such as the PR, thrust, and torque collected during drilling. While collecting these data, it was recorded that both thrust and torque would change substantially for different combinations of PR and bit speed. Besides, the model generated employing these data was well correlated with UCS. Finfinger et al [14] assessed the overlaying rock bed characteristics during the rock bolting process. An in-built monitoring system of a rock bolting machine could determine the thrust and torque during the same operation. It was reported that there was a substantial change of both parameters while the bit was progressing through the various layers of rocks that have different rock strength. During the drilling of marble, Bhatnagar et al [8] examined the effect of frequency of bit rotation on thrust and torque. From the test data, it was noticed that both thrust and torque would vary almost in the same way at different bit speed. In a rock drilling, the torque and penetration rate of the drill bit could largely influence by operating thrust and speed [23]. Sreenivasulu and Rao [26] studied the significant effect of drill bit diameter, penetration rate, and spindle speed on the bit force 
and torque while the aluminum alloy is drilling. Analysis of data revealed that bit speed and its diameter impacted both bit force and torque significantly. Lakshminarayana et al [20] used measurement while drilling technique to estimate the UCS. From the results, it was reported that thrust would vary linearly as the UCS of rocks increases. During the rotary drilling, Shankar et al [25] attempted to investigate the wear rate of the tungsten carbide drill bit. From the collected data, it could see that the thrust would significantly increase with an increase of UCS of drilling rocks. In a rock drilling, Chugh [11] found that the torque producing at the drilling point depends upon drilling parameters such as bit thrust, bit diameter, and the friction inducing between the bit-rock interfaces. During the rotary drilling of a cortical bone, the impact of rotational speed and PR of the drill bit on drill-bit thrust and rotational force was investigated by Alam et al [1]. The experimental data indicated that both thrust and torque were reduced by $27 \%$ and $30 \%$ respectively at the bit speed range of 600-3000 r.p.m. During a percussive type of rock drilling, Vardhan et al [28] observed that the acoustic parameter generating at the drilling point rises as the drill bit-thrust and rock strength increases. Kumar et al $[18,19]$ carry out a rotary drilling experiment to quantify UCS of sedimentary and metamorphic rocks respectively. The experimental results uncovered that sound level producing at the drilling point is the function of rock strength and drill operating parameters. It was also observed that the emanating sound was linearly varying with UCS of rocks. Yari and Bagherpour [32,33] and Vijay et al [29-31] conducted the drilling experiment with different combinations of drill operating variables such as penetration rate, drill diameter and its speed. For each combination of drill operating variables, an acoustic parameter was acquiring with the help of a data acquisition system (DAQ). The experimental results conclude that the acoustic parameter difference is because of different drill operating parameters and rocks with different strengths.

The above literature survey concludes that only a couple of studies estimated the rock strength based on applied thrust and penetration rate. In most of the previous studies, it is observed that the drilling responses such as thrust and torque are only analyzed concerning the rock strength, but both are not directly used to estimate the rock strength. Besides, in many mining activities, drilling is part of it. This method can determine the rock strength directly at the site using suitable thrust and torque sensors. The present work is entirely different from the previous studies and has many advantages over other methods. Therefore an attempt is made to estimate the rock strength using this method.

In this work, the relationship of drilling specific energy with the UCS of drilled rocks is also investigated. Behboud et al [7] attempted to correlate the specific energy of drilling with rock strength property such as UCS. From the results, it was concluded that the compressive strength is the most important geo-mechanical parameter affecting specific energy. The specific energy was almost linearly varying with an increase of UCS during rotary drilling of rocks $[10,16]$. During the rock drilling, using a blunt bit, Kalantari et al [17] found that a linear relationship exists between drilling specific energy and rock strength (UCS). Balci and Bilgin [3, 4] and Copur et al [12] investigated the relationship between specific energy utilized during the rock cutting and mechanical properties of rocks such as UCS, Brazilian tensile strength (BTS). From the results, it could see that the specific energy was well correlating with UCS. 
From the above-discussed literature, it was observed that the variation of drilling parameters such as thrust and torque is significant during drilling of different rocks. Therefore, the drill operating parameters can be possible variables to characterize the rock strength during the drilling. The main intention of this work is to investigate the usability of some identified drill operating parameters to predict the rock strength property and also to check the relationship of specific energy utilized during rock drilling with the uniaxial compressive strength of drilled rocks. In the present studies, an experimental setup was used to investigate the main objectives of this research work.

\section{Experimental setup and studies}

The configuration of the experiment is showing in the Fig. 1. It consists of a CNC vertical drilling machine, a drill dynamometer, and sedimentary rock blocks. A CNC drilling machine is utilize to accomplish the drilling of rocks with the help of diamond core drill bit of diameter 12, 16 and $20 \mathrm{~mm}$. The thrust producing at the drilling point is measuring with the aid of the drill dynamometer. A numerical control (NC) program could control the PR and bit speed during the drilling. The prepared cubical rock samples of size $15 \mathrm{~cm}$, including shale, sandstone, and limestones that have various UCS is using for experimental drilling purposes. The machine vice is used to fix the rock samples securely. The flaws of rock samples were checked during their collection.

An outline of the test program is showing in Fig. 2. While the drilling of various rocks at different drill working conditions, the corresponding thrust was measured with a device called drill tool dynamometer. The limit of measuring instrument was $1 \mathrm{~N}-5000 \mathrm{~N}$ with an LC of $1 \mathrm{~N}$. The dynamometer consists of a durable metal cylinder of height approximately $150 \mathrm{~mm}$ with $10 \mathrm{~mm}$ thick steel plates fitted at both top and undersides. The provisions are made on top and underside plates to fix securely to machine vice and machine bed, respectively, using the appropriate fasteners. Since the machine

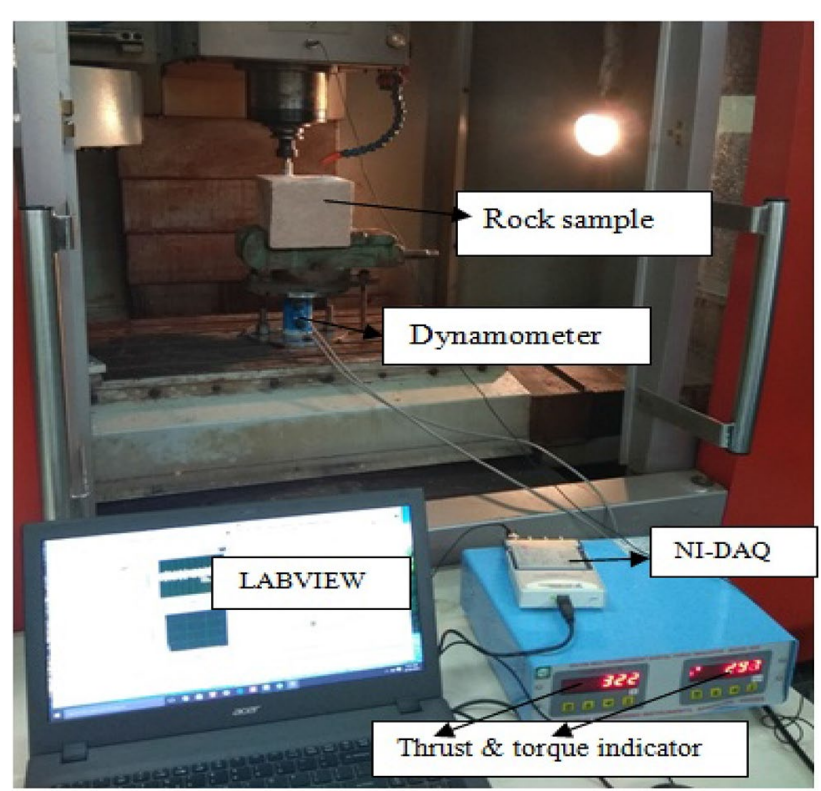

Fig. 1 Experimental setup 


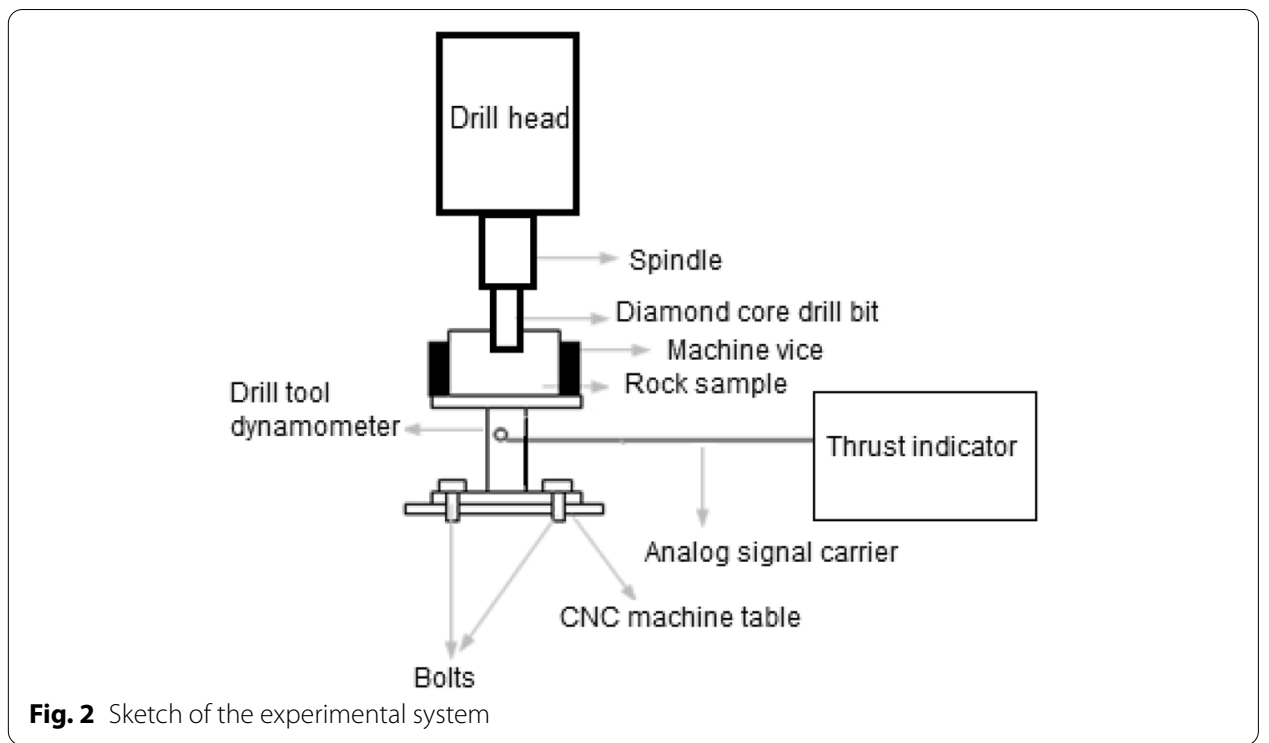

vice is directly fastening on the top of the dynamometer, the drilling of different rocks at a particular combination of machine operational parameters, the equivalent thrust would be exerting on the dynamometer and hence on its sensing material. Because of this physical phenomenon, the equal analog signal is emerging from the dynamometer device. Next, it switched into a digital signal through a signal conditioner and, in the end, could see the digital thrust reading in the dynamometer's display.

\section{Methodology}

In this method, the drilling of each type of sedimentary rock is carrying out at a various set of machine operating parameters. For each machine condition, the thrust exerting on the drill bit was recorded using the drill dynamometer. The specimen of cubical size $15 \mathrm{~cm} \times 15 \mathrm{~cm} \times 15 \mathrm{~cm}$ is tightly fixing in a rigid vice. Before drilling the rock blocks of each type, the blocks are entirely drying using an electric oven. The main intention of the drying process was to extract the moisture content from the rock blocks, and thereby to reduce the influence of moisture content on the strength of rocks.

With the help of diamond core drill bits, 9 different holes that have a depth of $30 \mathrm{~mm}$ were drilled on each rock type using the 9 combinations of drilling operational parameter (Drill bit diameter of 12, 16 and $20 \mathrm{~mm} \times$ speed of 500,700 and $900 \mathrm{rpm} \times$ penetration speed of $4 \mathrm{~mm} / \mathrm{min}$ ). A pipe carrying the compressed air is often directing towards the interaction of bit-hole during the drilling of each hole. Using the compressed air was to minimize the compaction effect by flushing out the rock dust-generating inside the hole and cooling the drill bit. The same procedure was repeated for drilling of all rock types. While the bit was advancing through a hole with the particular operating condition, the magnitude of thrust inducing at the drilling spot was changing. As the bit reaches the hole depth of $5,10,15,20,25$, and $30 \mathrm{~mm}$ depth, the six bit-thrust reading is taking down successively using the display unit of the dynamometer. Later the arithmetic average of six thrusts was calculated for that particular drilling operation. In the current experiment, a data set containing the 54 thrust readings would record during the 
entire drilling process ( 9 sets of machine operating conditions used for each rock type $\times 6$ types of rocks). Similarly, 54 sets of torque were computed for 54 corresponding thrusts using the Chugh [11] torque relationship, derived for a diamond core drill bit, as shown in the Eq. 1.

$$
\text { Torque }=\frac{2}{3} \times \mu \times \mathrm{T} \times \frac{\left(r_{o}^{3}-r_{i}^{3}\right)}{\left(r_{o}^{2}-r_{i}^{2}\right)}(N-m)
$$

where,

$\mathrm{T}=$ Bit thrust (n),

$r_{0}=$ Outer radius of bit $(m)$,

$\mathrm{r}_{\mathrm{i}}=$ Inner radius of bit $(\mathrm{m})$,

$\mu=$ Coefficient of friction between rock and diamond core bit.

The value of $\mu$, as suggested by Chugh [11] for rock material is 0.4

The laboratory testing for UCS is carried out using five rock samples and determined according to the guidelines recommended by the International Society for Rock Mechanics [9]. The rock core samples are also completely dry using an electric oven before testing them for UCS in a laboratory. The main mineralogical composition, such as analysis of silica content $\left(\mathrm{SiO}_{2}\right)$ of each rock type, would determine using the scanning electron microscope.

\section{Analysis of data}

When the drilling is carrying out for various rock types using the different bit diameter and speed, the variation of the bit-thrust is intricately affected by several features. Hence, the drilling process is illustrating by higher order regression model. Statistical application software Minitab 18 was utilized for the analysis of data. A total of 54 data were employed for developing the multiple regression models for UCS. The ANOVA approach analyzed the overall examination of the significance of each factor on the response (UCS). The diameter (D) of the drill bit, rotational speed (S), and penetration rate $(\mathrm{PR})$ is the drill working parameter. Similarly, the measured and computed machine operating parameters are thrust (T) produced on the drill bit and torque (TQ) developed at the bit-rock interface, respectively. During the drilling action, it is hypothesized that the change of thrust is due to using a different set of drill operating conditions and rock strength. The change of thrust while drilling is well associating with machine operating settings and rock strength $[1,3,5,14,15,18-20,23-25]$. The equation, as shown below, can imply the drilling process.

$$
\mathrm{f}=\mathrm{a}_{\mathrm{o}}+\sum_{\mathrm{i}=1}^{\mathrm{n}} \mathrm{a}_{\mathrm{i}} \mathrm{x}_{\mathrm{i}}+\sum_{\mathrm{i}=1}^{\mathrm{n}} \mathrm{a}_{\mathrm{ij}} \mathrm{x}_{\mathrm{i}}^{2}+\sum_{\mathrm{i}<j}^{\mathrm{n}} \mathrm{a}_{\mathrm{ij}} \mathrm{x}_{\mathrm{i}}+\epsilon
$$

In Eq. 2, $\mathrm{a}_{\mathrm{o}}$ indicates the arbitrary constant, $\mathrm{a}_{\mathrm{i}}$ signifies the straight source of xi, aij outlines the rectilinear source of $\mathrm{xi}$, and aij presented in the fourth term is produced due to the multiplied results of $x i$ and $x j$. The last term denoted by $\in$ represents the error. The backward elimination approach was chosen as a screening mode. The relevance of each regression term with the response is checking with the $\mathrm{t}$-test method. In the $\mathrm{t}$-test, the calculated $t$-value must always be higher than the tabulated $t$ value at a $95 \%$ confidence 
level and generated a degree of freedom. The regression term is selected if this condition is satisfying. Suppose any regression term is not satisfying this condition. In that case, that variable would remove from the model. Further simulation of the regression process is repeated using the survived variables until the remaining factors or variables could not remove from the model. Ultimately, the variables still remained in the model is chosen for a specific response. The predictive capacity of the regression model developed for UCS is checked using the performance indices such as variance account for (VAF), root mean square (RMSE) and mean absolute percentage error (MAPE) are used to evaluate the prediction capacity of the model.

$$
\begin{aligned}
& V A F=\left[1-\frac{\operatorname{var}(m-p)}{\operatorname{var}(m)}\right] \times 100 \\
& R M S E=\sqrt{\frac{1}{N} \sum_{i=1}^{N}(m-p)^{2}} \\
& \text { MAPE }=\frac{1}{N} \sum_{i=1}^{N}\left|\frac{(m-p)}{m}\right| \times 100
\end{aligned}
$$

In Eq. (3), (4) and (5), ' $m$ ' and 'p' indicating the UCS obtained in the test center and using the model, respectively, and $\mathrm{N}$ is the data size. In a model, a higher VAF value nearer to $100 \%$ indicates that the independent variables are explaining the variance in the dependent variable excellently. Similarly, if RMSE and MAPE values are close to zero value on a scale of 0 to100 concludes that the prediction error is low and accuracy of prediction is high, respectively.

\section{Result and discussions}

The UCS value of rocks found in the laboratory, and upper-lower values of measured thrust and calculated torque, and specific energy are tabulating in Table 1.

In this experiment, a $\mathrm{CNC}$ vertical drilling machine designed for a heavy-duty purpose is using to drill the various sedimentary rocks. The penetration rate (PR) and speed, which are the part of a different set of drill operating conditions, are

\begin{tabular}{|c|c|c|c|c|c|c|c|}
\hline \multirow[t]{2}{*}{ Rocks } & \multirow{2}{*}{$\begin{array}{l}\text { UCS } \\
\text { (MPa) }\end{array}$} & \multirow{2}{*}{$\begin{array}{l}\mathrm{SiO}_{2} \\
\text { content }\end{array}$} & \multicolumn{2}{|c|}{ Thrust (N) } & \multicolumn{2}{|c|}{ Torque $(\mathrm{N}-\mathrm{m})$} & \multirow{2}{*}{$\begin{array}{l}\text { Average specific } \\
\text { energy }\left(G J / m^{3}\right)\end{array}$} \\
\hline & & & Min & $\operatorname{Max}$ & Min & $\operatorname{Max}$ & \\
\hline Shale & 19.6 & $21 \%$ & 419 & 529 & 0.84 & 1.89 & 7.37 \\
\hline Fine grained sandstone- 1 & 42.1 & $31 \%$ & 472 & 560 & 0.95 & 2.00 & 8.16 \\
\hline Fine grained sandstone-2 & 65.3 & $35 \%$ & 501 & 625 & 1.01 & 2.23 & 8.95 \\
\hline Fine grained sandstone-3 & 76.6 & $42 \%$ & 535 & 660 & 1.07 & 2.35 & 9.41 \\
\hline Limestone-1 & 91.2 & $1.5 \%$ & 549 & 725 & 1.10 & 2.58 & 9.72 \\
\hline Limestone-2 & 119.0 & $1.9 \%$ & 619 & 812 & 1.25 & 2.89 & 10.2 \\
\hline
\end{tabular}

Table 1 Rock property and minimum and maximum value of measured thrust, computed torque and average specific energy 


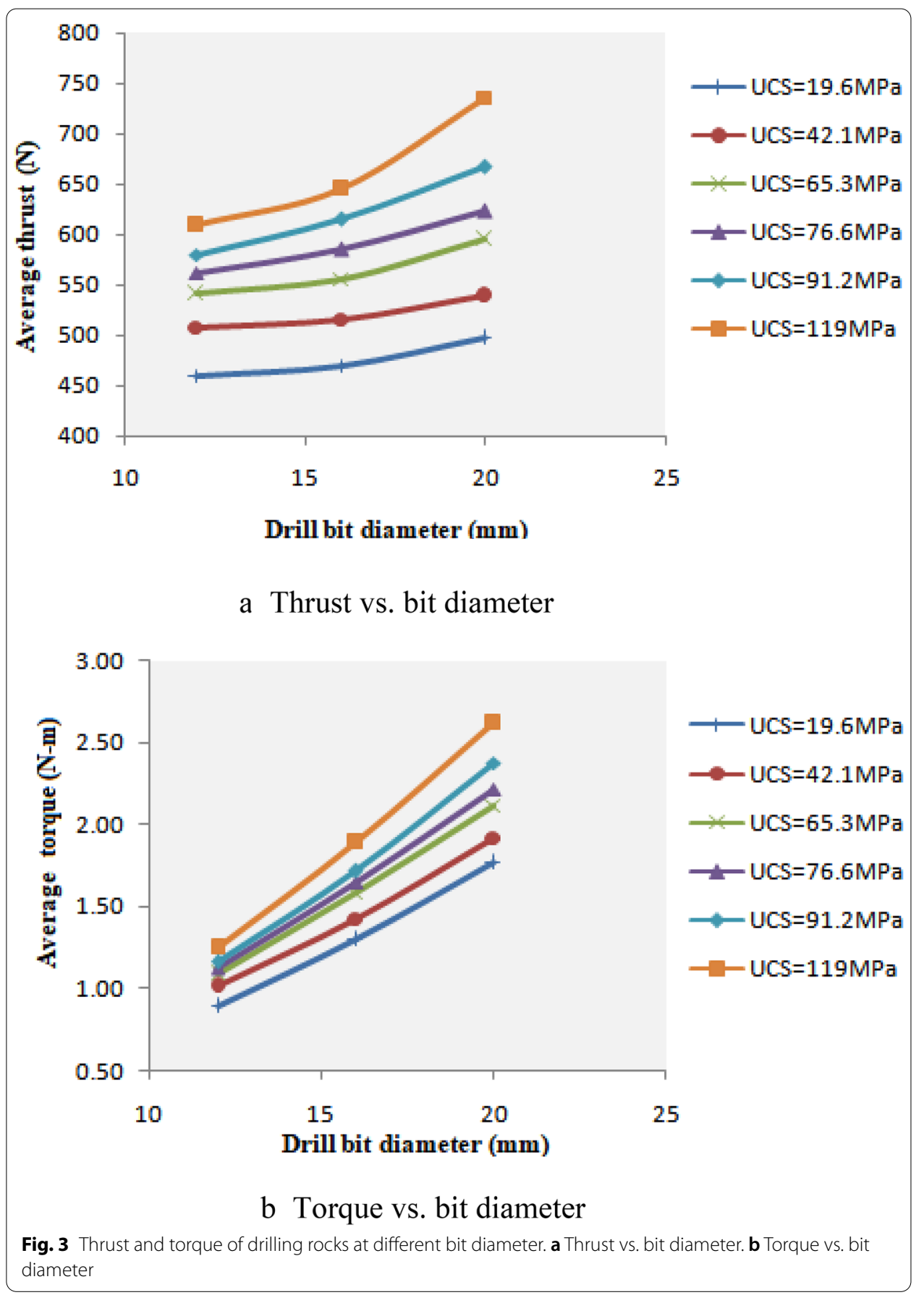

controlling by the numerical control program (NC program). The control system used in the CNC machine is a closed-loop type. So that, once the PR and speed are fixing in the CNC machine, irrespective of the strength and other properties of rocks, the drill bit could penetrate the material at constant specified PR $(\mathrm{mm} / \mathrm{min})$. During the drilling of different strength materials with specific speed, and diameter of the bit, the computer assists the machine to determine the required thrust accordingly. At last, it would apply the same bit-thrust to gain the preset penetration rate. Figure 3 
shows the variation of average measured thrust and theoretical torque inducing during the drilling of various rocks using different drill bit diameter. From Fig. 3a, it is observing that the thrust is steadily rising exponentially when the drill bit diameter is increasing. This may be because as the drilling hole area increases, the volume of the material removal rate also increases. The machine would utilize much thrust to maintain the preset penetration rate for a higher volume removal rate. It could also observe that the thrust level was significantly rising when the higher UCS rocks were drilling. It may occur because as the packing density of grains or degree of compactness increases in fine-grained rocks, the rock strength or UCS increases. The higher packing density of grains may offer more resistance against the penetration of bit at a particular speed. Hence, the CNC machine might utilize more bit-thrust to achieve a particular penetration rate of $4 \mathrm{~mm} / \mathrm{min}$. From Fig. 3b, it was noted that the torque was also gradually increased when the different UCS rocks being drilled using the different diameter bits. In general, torque is the function of bit-thrust and radius of drill bit. As these two variables increases, the torque also increases. However, in this experiment, the torque is calculated using the Eq. 1. In this equation, it is clearing that the torque is mainly the function of two variables such as drill bit radius or diameter and generated thrust. Therefore, the torque is increasing with increase of bit diameter and UCS.

Figure 4 indicates how the average thrust and torque varies at different speeds during the drilling of various sedimentary rocks. From Fig. 4a, it was seen that the thrust is linearly increasing between the bit speeds of 500-700 r.p.m. But, it is slightly reducing after the speed of 700 r.p.m. The drilling energy consists of two components, including thrust and rotational energy, as shown in Eq. 8. The reason may be concerning to Eq. 8 that the axial and cutting action may be assisted largely by rotational energy rather than the thrust for particular drilling energy at high spindle speed. Thus the thrust energy may reduce slightly at high spindle speed.

As shown in Fig. 4b, torque could vary almost in the same way as a thrust at a different speed [11, 12]. Figure 5 depicts the association between average thrust and torque inducing during the drilling of different sedimentary rocks. It is observing that both the average thrust and torque of various rocks are varying linearly.

The following model is drawn from the set of drill operating variables to predict the UCS,

$$
U C S=75.3-0.7201 \times S+0.5168 \times T-29.66 \times T Q+0.000479 \times S \times S
$$

The model formulated for the evaluation of UCS is shown in Eq. 3. Table 2A explains that the generated model is responsible for $93.60 \%$ of the entire variation in response, i.e., UCS. Since the $\mathrm{R}^{2}$ value is nearer to $100 \%$, the integral explanation of variance in the dependent variable by input parameters is highly significant. From Table $2 \mathrm{~B}$, it is cleared that each variable is statistically significant at a $95 \%$ confidence level, as $\mathrm{p}<0.05$ and generated $\mathrm{t}>$ tabulated $\mathrm{t}$ (For generated DOF $=4$, Total DOF $=$ generated DOF-1, standard $t=2.353$ ). At $95 \%$ confidence level, the value of $p$ less than 0.05 indicates that the probability of not occurring the relationship between independent and dependent variables is less than $5 \%$. Therefore the null hypothesis is rejected, and the alternate hypothesis concludes that there is a relationship between independent and dependent variables. Hence, 


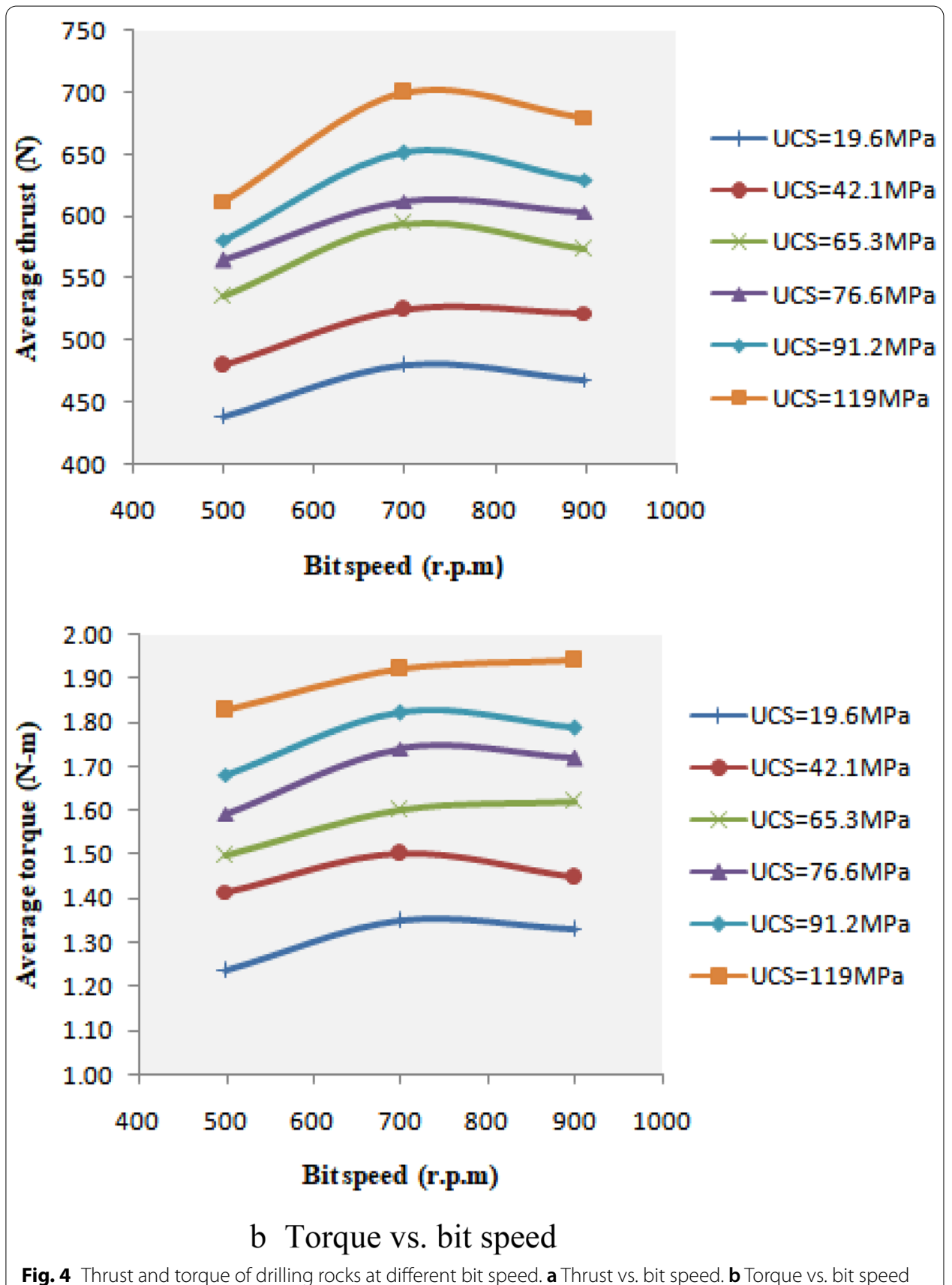

it could conclude that the variables included in the UCS model are affecting the UCS. Since the p-value of drill bit diameter was higher than the value of 0.05 , it is confirming that the drill bit diameter is not influencing the response (UCS) directly, and it is excluding from the model.

Among the drilling responses such as thrust and torque, the higher the adjusted and the sum of squares and corresponding F-value indicate that a particular drilling response would impact the UCS than the other one. In the ANOVA Table $2 \mathrm{C}$, the value of the 


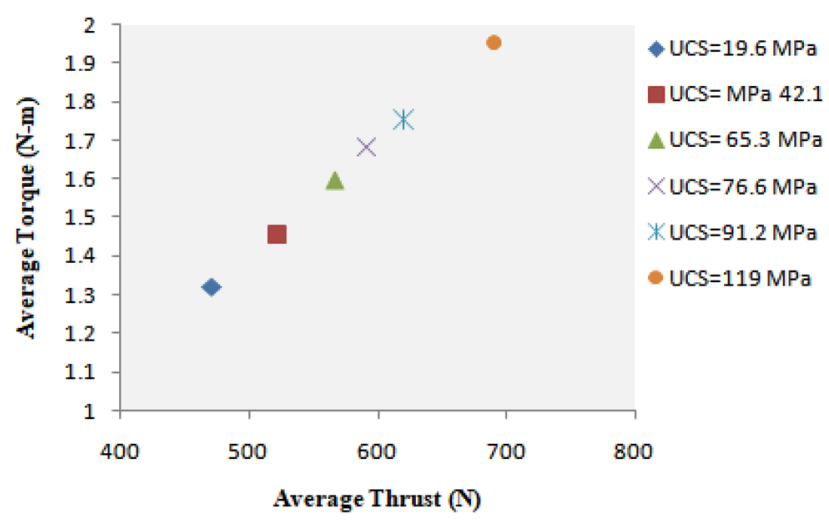

Fig. 5 Association of torque and thrust

Table 2 Statistical results of model

\begin{tabular}{|c|c|c|c|c|}
\hline \multicolumn{5}{|c|}{ A:Illustration of model (UCS) } \\
\hline$\overline{R^{2}}$ & \multicolumn{2}{|l|}{ Adjusted $\mathrm{R}^{2}$} & Predicted $\mathrm{R}^{2}$ & Error \\
\hline 93.60 & \multicolumn{2}{|l|}{93.07} & 91.90 & 8.45 \\
\hline \multicolumn{5}{|c|}{ B:The importance of model } \\
\hline Factors & \multicolumn{2}{|l|}{ Coefficients } & t-value & p-value \\
\hline Constant & \multicolumn{2}{|l|}{75.3} & 2.59 & 0.013 \\
\hline S & \multicolumn{2}{|l|}{-0.7201} & -7.93 & 0.000 \\
\hline $\mathrm{T}$ & \multicolumn{2}{|l|}{0.5168} & 24.19 & 0.000 \\
\hline TQ & \multicolumn{2}{|l|}{-29.66} & -8.89 & 0.000 \\
\hline$S \times S$ & \multicolumn{2}{|l|}{0.000479} & 7.45 & 0.000 \\
\hline \multicolumn{5}{|l|}{ C:ANOVA } \\
\hline Factors & DF & Adj SS & F-value & p-value \\
\hline Regression & 04 & 52464 & 179.03 & 0.000 \\
\hline S & 1 & 4602 & 62.81 & 0.000 \\
\hline T & 1 & 42864 & 585.07 & 0.000 \\
\hline TQ & 1 & 5782 & 78.92 & 0.000 \\
\hline$S \times S$ & 1 & 4068 & 55.53 & 0.000 \\
\hline Error & 49 & 3590 & - & - \\
\hline Total & 53 & 56054 & - & - \\
\hline
\end{tabular}

adjusted sum of the square (Adj SS) and corresponding F-value is high for thrust. Therefore, it can be concluded that thrust is the variable that is much impacting the UCS. Also, the overall F-value of regression is high implies that the fitting of the data to the model is good. The model formulated for the evaluation of UCS is shown in Eq. 3. Figure 6 intimates that how far the UCS evaluated in the laboratory is closely correlated with the UCS determined by the developed model.

Table 3 illustrates the performance evaluated for the developed UCS model. The VAF is close to $100 \%$ indicating the very good variance of input parameters in UCS, similarly the RMSE and MAPE is less than $15 \%$, the model would predict the UCS 


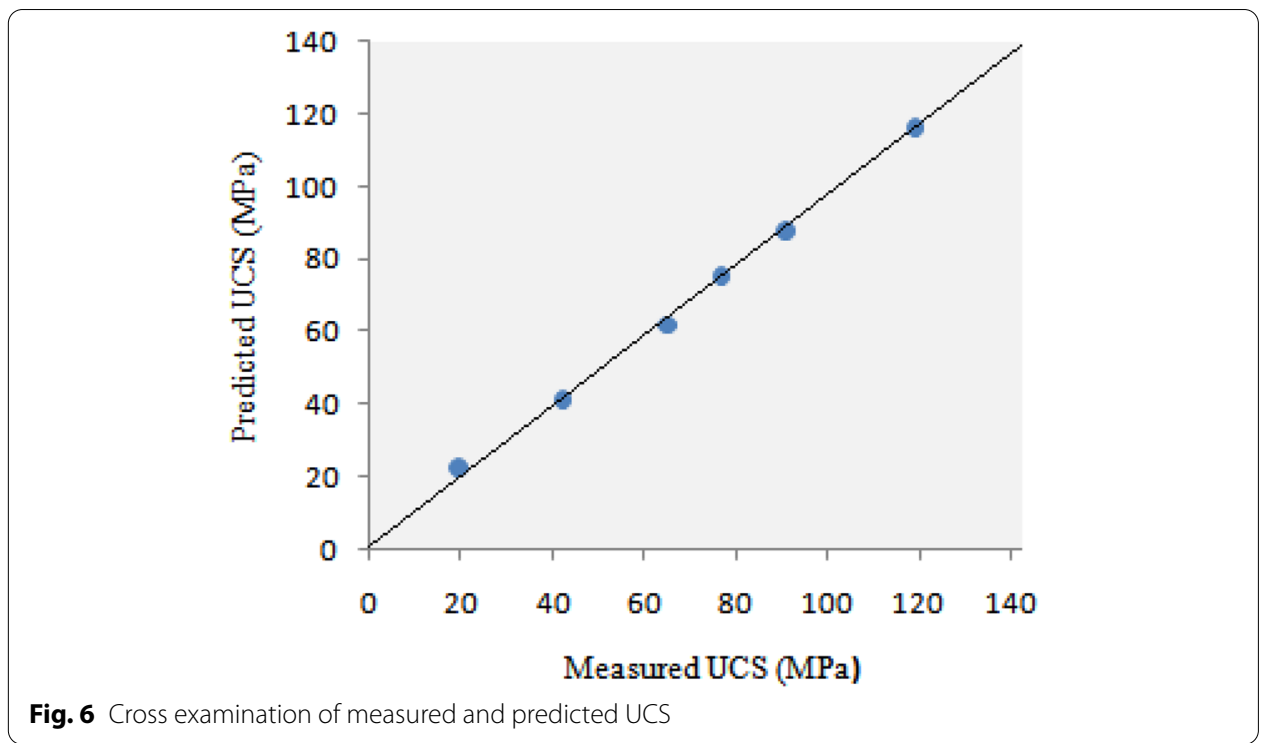

Table 3 Quantification of prediction capacity of UCS model

\begin{tabular}{llll}
\hline Dependent variable & \multicolumn{2}{l}{ Indices } & \\
\cline { 2 - 4 } & VAF (\%) & RMSE & MAPE (\%) \\
\hline UCS (MPa) & 93.59 & 4.159 & 11.27 \\
\hline
\end{tabular}

within acceptable error limits, and accuracy respectively. However, the derived model's validation is checked for a set of sandstone and limestone having UCS $28 \mathrm{MPa}$ and $35 \mathrm{MPa}$, respectively. The value of thrusts are acquired for both rocks at the constant penetration rate of $4 \mathrm{~mm} / \mathrm{min}$, bit diameter of $12 \mathrm{~mm}, 16 \mathrm{~mm}$, and $20 \mathrm{~mm}$ using the different speeds 500,700 and 900 r.p.m. The result shows that the model could predict the average UCS of sandstone and limestone with an error of $2.4 \mathrm{Mpa}$ and $2.8 \mathrm{Mpa}$, respectively. In terms of percentage, the prediction error for sandstone and limestone are $8.51 \%$ and $8.01 \%$, respectively. Since the errors are within the acceptable limit, usually $15 \%$, it is concluded that the developed regression model for UCS may reasonably predict the UCS for sedimentary rock types.

\section{Relationship between specific energy of drilling and the UCS}

In rock drilling, specific energy is the minimum amount of energy required for removing the unit volume of rock. In this study, an attempt is also made to find the relationship between specific energy and UCS of rocks. The relationship between specific energy and UCS is investigating using a linear regression method. In the current work, the specific energy is calculating with the use of obtained thrust and torque for each machine operational conditions. The equation for specific energy during rotary drilling was derived by Teale [27] in 1965 and is given by 


$$
E=\frac{F}{A}+\frac{2 \times \pi \times N \times T_{q}}{A \times P R} \mathrm{~J} / \mathrm{m}^{3}
$$

The Eq. (7) basically consists of two components and it can be written as

$$
E=E_{T}+E_{R}
$$

The first component in Eq. (8) of the equation represents the contribution of thrust (thrust component) and the second component is representing the rotary component of energy (torque component).

E - Specific energy $\left(\mathrm{J} / \mathrm{m}^{3}\right)$,

F - Thrust acting on the bit (Newton),

A - Area removed $\left(\mathrm{m}^{2}\right)$,

$\mathrm{N}-$ Drill bit speed (r.p.s),

$\mathrm{Tq}$-Torque developed at bit rock interface corresponding to the applied thrust $(\mathrm{N}-\mathrm{m})$,

$\mathrm{PR}$-Penetration rate $(\mathrm{m} / \mathrm{sec})$.

The average specific energy for each rock type is tabulating in Table 1. From Fig. 7, it was seen that the relationship between specific energy and UCS of drilled rocks is very good with an $r^{2}$ value of $92 \%$.

\section{Conclusions}

In this investigation, the rock strength property, such as UCS would approximately quantify using the machine operating variables used for managing the drilling process. The drill tool dynamometer was employed to measure the drilling response parameter such as thrust, and corresponding torque could calculate with measured thrust and drill

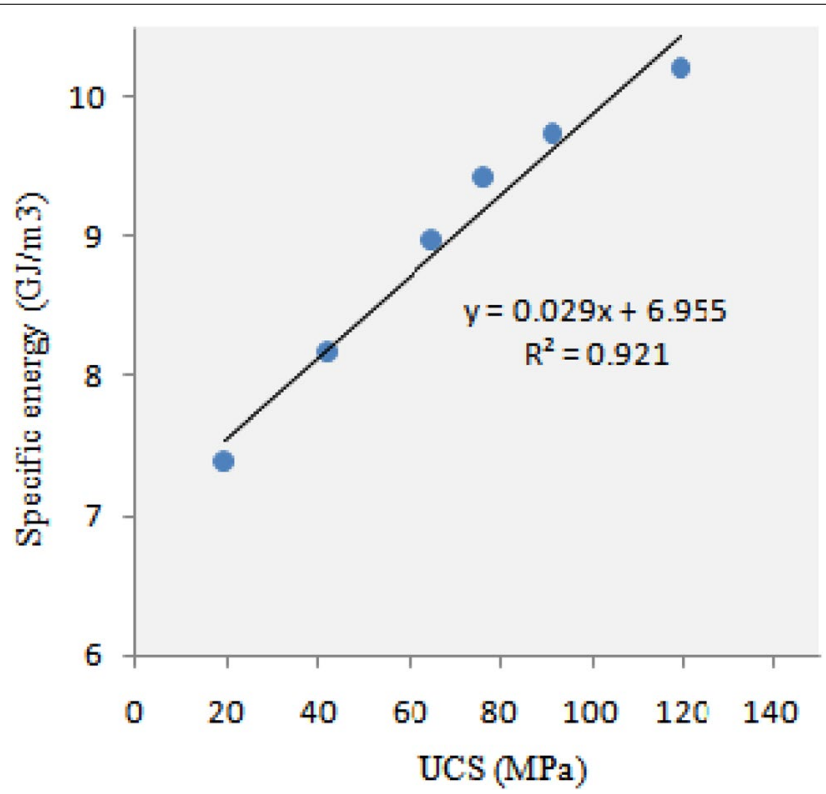

Fig. 7 Relationship between specific energy and UCS of rocks 
bit diameter. From the experimental results, the following results and conclusions were obtained.

- When the rocks that have different UCS are drilling, it is observing that the drill operating parameters such as thrust and torque was substantially increased from 419 to $812 \mathrm{~N}(48.39 \%)$ and $0.84 \mathrm{~N}-\mathrm{m}$ to $2.89 \mathrm{~N}-\mathrm{m}$ (70.39\%) respectively.

- During the drilling of rocks, when the drill bit diameter changed from 12 to $20 \mathrm{~mm}$, the overall percentage of increase in thrust for rocks having the UCS of 19.6, 42.1, 65.3, 76.6, 91.2 and $119 \mathrm{MPa}$ was 10.38\%, 5.82\%, 9.04\%, 9.62\%,12.76\%, and $11.19 \%$ respectively.

- Similarly, when the drill bit diameter changed from 12 to $20 \mathrm{~mm}$, the overall percentage of increase in computed torque for rocks having the UCS of 19.6, 42.1, 65.3, 76.6, 91.2 and $119 \mathrm{MPa}$ was 42.55\%, 43.58\%, 40.79\%, 42.12\%, 49.88\%, and 50\% respectively.

- From the adjusted SS value and equivalent F-value as shown in the ANOVA table, it was concluded that the main interesting drilling variables such as thrust (Adjusted SS value $=42864$, F-Value $=585.07$ ) and torque (Adjusted SS value $=5782$, F-Value $=78.92)$ are respectively impacting the UCS.

- The evaluation of regression model indicated that the model could estimate the UCS with an overall percentage error of $3.49 \%$ and the mean absolute percentage error of $11.27 \%$. The validation model for sandstone and limestone would also predict the UCS with the error of $8.51 \%$ and $8.01 \%$.

- The evaluation of the model using both prediction indices and validation techniques revealed that the developed model would predict the UCS below the 15\% prediction error. In general, it could be considered as acceptable limits for estimation purposes.

- The relationship between specific energy utilized during drilling of different rocks and their UCS are having an almost linear relationship, with a coefficient of determination $\left(R^{2}\right)$ value of $92.1 \%$.

\section{Authors' contributions}

This research is being done with the integral effort of all three authors. Mr. CR L first author has carried out the study and also wrote the entire manuscript under the guidance of other two authors. Dr. AKT has supervised this study. Prof. SK P also supervised this study in numerous ways. All authors have read and approved the final manuscript.

\section{Author details}

${ }^{1}$ Department of Mining Engineering, N.I.T.K, Surathkal, Mangalore 575025, Karnataka, India. ${ }^{2}$ Department of Mining Engineering, IIT, Kharagpur 721302, West Bengal, India.

Received: 13 October 2020 Accepted: 7 April 2021

Published online: 24 August 2021

\section{References}

1. Alam K, Mitrofanov A, Silberschmidt V (2011) Experimental investigations of forces and torque in conventional and ultrasonically-assisted drilling of cortical bone. Med Eng Phys 33:234-239. https://doi.org/10.1016/j.medengphy. 2010.10 .003

2. Altindag R (2002) The evaluation of rock brittleness concept on rotary blast hole drills. J South Afr Inst Min Metall 102:61-66

3. Balci C, Bilgin N (2001) Estimating the specific energy from rock properties for selection of rapid excavation systems In 10th Int. Symp. on Mine Planning and Equipment Selection, New Delhi. pp. 393-400

4. Balci C (2004) Comparison of small scale and full scale rock cutting tests to select mechanized excavation machines. Ph.D. Thesis, Istanbul Technical University 
5. Basarir H, Wesseloo J, Karrech A, Pasternak E, Dyskin A. (2017) The use of soft computing methods for the prediction of rock properties based on measurement while drilling data. In 8th International Conference on Deep and High Stress Mining. (pp. 537-551). Australian Centre for Geomechanics.https://doi.org/10.36487/ACG_rep/1704_36_Basar ir

6. Basarir H, Karpuz C (2016) Preliminary estimation of rock mass strength using diamond bit drilling operational parameters. Int J Min Reclam Environ 30:145-164. https://doi.org/10.1080/17480930.2015.1025561

7. Behboud MM, Ramezanzadeh A, Tokhmechi B (2017) Studying empirical correlation between drilling specific energy and geo-mechanical parameters in an oil field in SW Iran. J Min Envir 8(3):393-401. https://doi.org/10.22044/ jme.2016.689

8. Bhatnagar A, Khandelwal M, Rao KUM (2011) Laboratory investigations for the role of flushing media in diamond drilling of marble. Rock Mech Rock Eng 44:349-356. https://doi.org/10.1007/s00603-011-0144-7

9. Brown ET (1981) ISRM rock characterization testing and monitoring suggested methods. Pergamon Press, Oxford

10. Celada B, Galera JM, Muñoz C, Tardáguila I. (2009) The use of the specific drilling energy for rock mass characterisation and TBM driving during tunnel construction. In ITA-AITES world tunnel congress, Budapest, Universidad Politcnica de Madrid, Spain. (pp. 1-13)

11. Chugh CP (1992) High technology in drilling and exploration, 1st edn. CRC Press, New Delhi

12. Copur $H$, Tuncdemir H, Bilgin N, Dincer T (2001) Specific energy as a criterion for use of rapid excavation systems in Turkish mines. Trans Institut Min Metall Sect A: Min Technol 110(3):149-157. https://doi.org/10.1179/mnt.2001.110.3. 149

13. Ersoy A, Waller MD (1995) Prediction of drill-bit performance using multi-variable linear regression analysis. Int J Rock Mech Min Sci Geomech Abstr 6:279A. https://doi.org/10.1016/0148-9062(95)99224-I

14. Finfinger G, Peng S, Gu Q, Wilson B, Thomas. (2000). An approach to identifying geological properties from roof bolter drilling parameters, In Proceedings of the 19th International Conference on Ground Control in Mining. West Virginia University, Morgantown (pp. 1-11)

15. Hatherly P, Leung R, Scheding S, Robinson D (2015) Drill monitoring results reveal geological conditions in blast hole drilling. Int J Rock Mech Min Sci 78:144-154. https://doi.org/10.1016/j.jirmms.2015.05.006

16. Huang SL, Wang ZW (1997) The mechanics of diamond core drilling of rocks. Int J Rock Mech Min Sci 34:3-4. https:// doi.org/10.1016/S1365-1609(97)00233-5

17. Kalantari S, Hashemolhosseini H, Baghbanan A (2018) Estimating rock strength parameters using drilling data. Int J Rock Mech Min Sci 104:45-52. https://doi.org/10.1016/j.jprmms.2018.02.013

18. Kumar BR, Vardhan G, Govindaraj M (2011) Prediction of uniaxial compressive strength, tensile strength and porosity of sedimentary rocks using sound level produced during rotary drilling. Rock Mech Rock Eng 44:613-620. https:// doi.org/10.1007/s00603-011-0160-7

19. Kumar BR, VardhanGovindaraj GM (2011) A new approach for estimation of properties of metamorphic rocks. Int J Min Miner Eng 3:109-123. https://doi.org/10.1504/IJMME.2011.042426

20. Lakshminarayana CR, Tripathi AK, Pal SK (2020) MWD technique to estimate the uniaxial compressive strength of rocks. In: AIP Conference Proceedings, Bengaluru, vol 2204. AIP Publishing LLC, Melville, pp 040011

21. Mohammad B, Robert H (2016) Processing of measurement while drilling data for rock mass characterization. Int J Min Sci Technol 26(6):989-994. https://doi.org/10.1016/j.ijmst.2016.09.005

22 Raghavan V, Murthy CHSN (2018) Prediction of cuttability from rock cutting resistance. J S Afr Inst Min Metall 118:321-329. https://doi.org/10.17159/2411-9717/2018/v118n3a14

23. Rao KUM, Bhatnagar A, Misra B (2002) Laboratory investigations on rotary diamond drilling. Geotech Geol Eng 20:1-16. https://doi.org/10.1023/A:1013864423562

24. Roxborough FF. (1987) The role of some basic rock properties in assessing cut ability. In proceedings of the seminar on tunnels. The University of New South Wales, Sydney, pp 1-18

25. Shankar VK, Kunar BM, Murthy CS (2020) Measurement of bit-rock interface temperature and wear rate of the tungsten carbide drill bit during rotary drilling. Friction 8:1073-1082. https://doi.org/10.1007/s40544-019-0330-2

26. Sreenivasulu R, Rao CS (2016) Effect of drilling parameters on thrust force and torque during drilling of aluminum 6061 alloy-based on taguchi design of experiments. J Mech Eng 46:41-48. https://doi.org/10.3329/jme.v46i1.32522

27. Teale R (1965) The concept of specific energy in rock drilling. Int J Rock Mech Min Sci Geomech Abstr 2:57-73

28. Vardhan H, Adhikari GR, Raj MG (2009) Estimating rock properties using sound levels produced during drilling. Int J Rock Mech Min Sci 46:604-612. https://doi.org/10.1016/j.jirmms.2008.07.011

29. Vijaya Kumar $\mathrm{CH}$, Vardhan H, Murthy CHSN (2019) Quantification of rock properties using frequency analysis during diamond core drilling operations. J Inst Eng India Ser D 100:67-81

30. Vijaya Kumar CH, Vardhan H, Murthy CHSN (2019) Multiple regression model for prediction of rock properties using acoustic frequency during core drilling operations. Geomech Geoeng. https://doi.org/10.1080/17486025.2019. 1641631

31. Vijaya Kumar $\mathrm{CH}$, Vardhan H, Murthy CHSN (2019) Estimating rock properties using sound signal dominant frequencies during diamond core drilling operations. J Rock Mech Geotech Eng. https://doi.org/10.1016/j.jrmge.2019.01. 001

32. Yari M, Bagherpour R (2018) Investigating an innovative model for dimensional sedimentary rocks characterization using acoustic frequencies analysis during drilling. Rudarsko Geolosko Naftni Zbornik 33(2):17-25. https://doi.org/ 10.17794/rgn.2018.2.2

33. Yari M, Bagherpour R (2018) Implementing acoustic frequency analysis for development the novel model of determining geomechanical features of igneous rocks using rotary drilling device. Geotech Geol Eng 36:1805-1816. https://doi.org/10.1007/s10706-017-0433-3

\section{Publisher's Note}

Springer Nature remains neutral with regard to jurisdictional claims in published maps and institutional affiliations. 